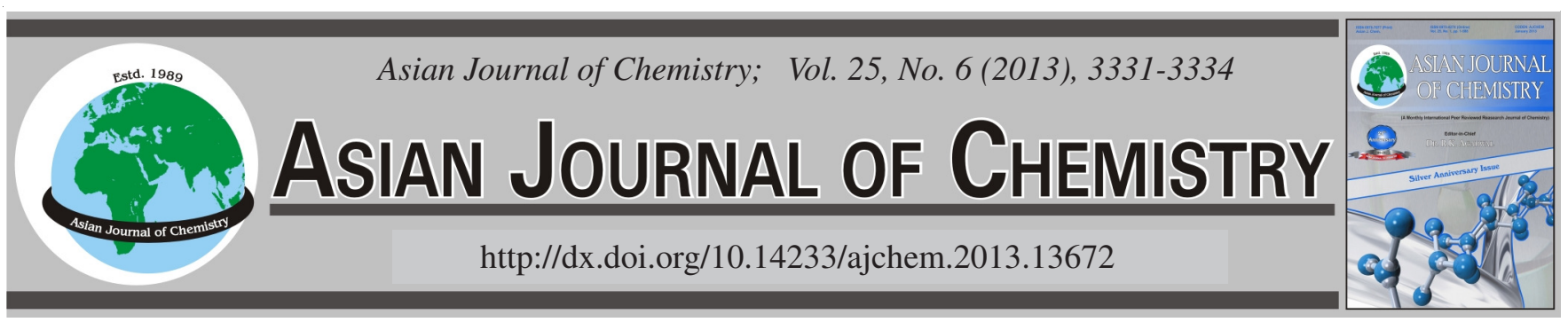

\title{
Degradation of Cyromazine in Cucumber and Soil
}

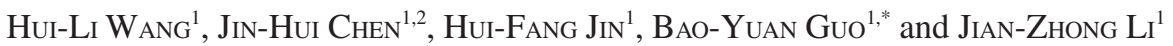

${ }^{1}$ Research Center for Eco-Environmental Sciences, Chinese Academy of Sciences, Beijing 100085, P.R. China

${ }^{2}$ Institute for the Control Agrochemicals, Ministry of Agriculture, Beijing 100026, P.R. China

*Corresponding author: Fax: +86 10 62849790; Tel: +86 10 62931475; E-mail: guoby@ rcees.ac.cn

(Received: 29 February 2012;

Accepted: 19 December 2012)

AJC-12579

\begin{abstract}
A high performance liquid chromatographic method was developed for the analysis of cyromazine in cucumber and soil to investigate the degradation of cyromazine in the two mediums. The declining kinetics of cyromazine was in accordance to the first order reaction kinetics and the average half-life of cyromazine was 5.2-7.3 days in cucumber, while was 10. 1-15.3 days in soil in three locations of Beijing, Anhui and Hainan of China. The degradation in Beijing was relatively slow and it was higher in Hainan than in other locations. The proharvest-interval was 3 days based on the experiments in the three locations and the maximum residual limit of $0.2 \mathrm{mg} / \mathrm{kg}$.
\end{abstract}

Key Words: Cyromazine, Reverse-phase liquid chromatography, Cucumber, Soil, Degradation.

\section{INTRODUCTION}

Cyromazine (2-cyclopropylamino-4,6-diamino-s-triazine) (Fig. 1), a triazine pesticide, was widely used for controlling flies on animals and leafminers on fruits, vegetables and ornamental plants ${ }^{1}$. Cyromazine could be metabolized by dealkylation to melamine ${ }^{2}$ and caused potential environmental risk and human health problems. Therefore, it is important to investigate the residues and degradation properties in environment and food production.

Gas chromatography has been described in the determination of cyromazine and its metabolites ${ }^{1,3}$. However, the preliminary derivatization procedures were required before GC analysis. Therefore, high-performance liquid chromatography (HPLC) was employed most often and various samples present were investigated using HPLC included chard ${ }^{4}$, poultry meat ${ }^{5}$, eggs ${ }^{5,6}$, milk $^{3}$ and soil ${ }^{7}$.

Since cyromazine was used widely, the residue of cyromazine on some vegetables has been reported. A new method for the analysis of cyromazine in soil and cucumber is developed, which used less organic solvent. Cucumber is one of the most popular vegetable in China and cyromazine was employed on cucumber often. To evaluate the application safety of cyromazine on cucumber, the degradation properties in soil and cucumbers in China was investagated. The residues in soil and cucumbers were investigated as well to evaluate the per-harvest interval according to the dietary in China.

\section{EXPERIMENTAL}

HPLC ananlysis was performed on Agilent 1100 HPLC system comprising an UV detector detected at $230 \mathrm{~nm}$ (Agilent,
USA). ODS column $\left(\mathrm{C}_{18}, 250 \mathrm{~mm} \times 4.6 \mathrm{~mm}\right.$ i.d., $5 \mathrm{~mm}$ particle) from Dikma (Beijing, China) was employed. The mobile phase was acetonitrile-water $2: 98$ with $0.05 \%$ phosphoric acid as additives and the flow rate was $1.0 \mathrm{~mL} / \mathrm{min}$. The samples should be filtered through a $0.45 \mathrm{~mm}$ nylon membrane before injection. After conditioning the $\mathrm{C}_{18}$ column with mobile phase at $25^{\circ} \mathrm{C}, 20 \mathrm{~mL}$ sample was injected.<smiles>Nc1nc(N)nc(NC2CC2)n1</smiles>

Fig. 1. Chemical structures of cyromazine

Acetonitrile was of HPLC grade form Dikama (Beijing, China); hydrochloric acid and ammonium acetate were analytical grade; phosphoric acid was of guaranteed reagent; and analytical standards of cyromazine $(99.0 \%)$ and $75 \%$ WG formulation were obtained from Beijing Centre for Organic Agriculture (Beijing, China).

Field trials: The field trial was carried out in three locations of Beijing, Anhui and Hainan. Cyromazine should not been used in the experiment famer land in recent years. A random $30 \mathrm{~m}^{2}$ scheme was used, with three replications for each test. The control plots were localized, tagged and separated 
TABLE-1

FIELD EXPERIMENT ARRANGEMENT IN THE EXPERIMENT

\begin{tabular}{|c|c|c|c|c|c|c|c|c|c|c|c|}
\hline & $\mathrm{B}$ & \multirow{7}{*}{ 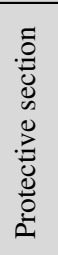 } & LDS A $_{1}$ & \multirow{7}{*}{ 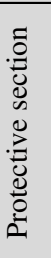 } & $\mathrm{HDS} \mathrm{A}_{2}$ & \multirow{7}{*}{ 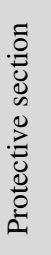 } & $\mathrm{HDS} \mathrm{B}_{1}$ & \multirow{7}{*}{ 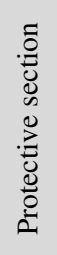 } & $\mathrm{LDS} \mathrm{B}_{2}$ & \multirow{7}{*}{ 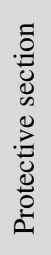 } & DS \\
\hline Area $/ \mathrm{m}^{2}$ & 30 & & 30 & & 30 & & 30 & & 30 & & 30 \\
\hline Dose G (a.i.)/ha & - & & 225 & & 337.5 & & 337.5 & & 225 & & 337.5 \\
\hline Spraying times & - & & 2 & & 2 & & 3 & & 3 & & 1 \\
\hline \multirow[t]{3}{*}{ Repetition } & - & & I & & I & & I & & I & & I \\
\hline & & & II & & II & & II & & II & & II \\
\hline & & & III & & III & & III & & III & & III \\
\hline
\end{tabular}

B means blank section with no cyromazine sprayed, which was sprayed with water. LDS means low dosage section; HDS means high concentration section; DS means degradation section

by guard rows to avoid contamination by each other. All the areas were receiving routine horticultural treatment. The trials were performed on May, 19, 2009. Cucumber was treated with the commercial formulation of cyromazine ( $75 \%$ cyromazine WG) with a hand operated Agrolex HD400 sprayer (Agrolex, Singapore). The field trail was planed and carried out accord to Table-1.

To evaluate the degradation dynamics of cyromazine in cucumber and field soil, the dosages of cyromazine of $337.5 \mathrm{~g}$ (a.i.)/ha (active ingredient, 1.5 folders to the recommended dosage) was applied in the cucumber and a blank land with no cucumber and other plants. Normal cucumber was collected randomly in the experiment section. Soil samples were collected from directly beneath the treated wheat plant in depths ranging from 0 to $10 \mathrm{~cm}$. The soil samples were collected at 0 (1 h after spraying), 1, 2, 3, 5, 7, 14, 21, 28, 35 and $42 \mathrm{~d}$ after spraying. Control samples were obtained from the soil under the control plots. Samples were kept at $-20{ }^{\circ} \mathrm{C}$ until analysis.

Two dosages of cyromazine were equivalent to 225 , $337.5 \mathrm{~g}$ (a.i.)/ha (active ingredient) with two and three times succession sprayings at $7 \mathrm{~d}$ intervals. Untreated plots were sprayed water as control. To evaluate the final residue in soil and cucumber, samples of cucumber were taken after 0 ( $1 \mathrm{~h}$ after spraying) 1, 2, 3, 5, $7 \mathrm{~d}$ after spraying by a five-spot sampling method. Soil sample was collected around the cucumber in the land ( 0 to $10 \mathrm{~cm}$ depth). The collected samples were cut into small pieces about $1 \mathrm{~cm}$ length and kept in a polyethylene bag and stored at $-20{ }^{\circ} \mathrm{C}$ until analysis.

Sample preparation: $10 \mathrm{~g}$ cucumber sample was extracted with acetonitrile-ammonium acetate $(9: 1)$ for three times $(50 \mathrm{~mL}, 20 \mathrm{~mL}, 20 \mathrm{~mL})$. The extraction was enhanced with ultrasound (in ultrasonic bath for $0.5 \mathrm{~h}$ ). During the second and third extraction, 10 min ultrasound was applied. After the extracted solutions was centrifuged for $10 \mathrm{~min}$ at $10,000 \mathrm{rpm}$ (3 K15 centrifuge from Sigma (Sigma, German). Followed the $\mathrm{pH}$ of supernatant was adjusted to $9-11$ and added $4 \mathrm{~g}$ of sodium chloride then left to stand for $15 \mathrm{~min}$. The acetonitrile phase was shifted to $250 \mathrm{~mL}$ volumetric flasks with $4 \mathrm{~g} \mathrm{NaCl}$; and water phase was extracted twice with $30 \mathrm{~mL}$ acetonitrile. Then, combined the acetonitrile extraction and evaporated to dryness. Finally, it redissolved in $2 \mathrm{~mL}$ dichloromethane and prepared to be subjected to purification.

The soil samples were crushed with a hammer mill or blended and then sieved to obtain same size granules ( $2 \mathrm{~mm}$ sieve). The pre-processor of soil samples was not complicated compared cucumber samples preparation. $20 \mathrm{~mL}$ hydrochloric acid $(50 \mathrm{mM})$ was added to $10 \mathrm{~g}$ soil samples. The mixture was placed in an ultrasonic bath for $20 \mathrm{~min}$. After that the extracted solutions was centrifuged for $10 \mathrm{~min}$ at 10,000 rpm (3 K15 centrifuge; sigma, German). Then it was evaporated to dryness and adding $20 \mathrm{~mL}$ methanol at a water bath temperature of $70{ }^{\circ} \mathrm{C}$. The following clean-up step was the same as clean-up step of cucumber samples.

In the procession of clean-up, $0.5 \mathrm{mg}$ silica gel which allowed to dry overnight at $120{ }^{\circ} \mathrm{C}$ was activated with $1 \%$ water and loaded in $1 \mathrm{~mL}$ cartridges. After that it was conditioned with $5 \mathrm{~mL}$ methanol then $15 \mathrm{~mL}$ dichloromethane. The solution containing cyromazine from extraction step was eluted with methanol-dichloromethane 1:3 (v:v) $5 \mathrm{~mL}$. Then eluate was evaporated to dryness at $35^{\circ} \mathrm{C}$ under a steam of nitrogen, followed it was re-dissolved in $1.0 \mathrm{~mL} \mathrm{2:} 98(\mathrm{v}: \mathrm{v})$ acetrotrilewater and was filtered through a 0.45 micropor membrane filter before HPLC analysis.

\section{RESULTS AND DISCUSSION}

Chromatography conditions and quantification: Since $\log \mathrm{P}$ of the pesticide was 2.92 , the mobile phase acetontrilewater 2:98 was employed and $0.05 \%$ of phosphoric acid was selected as a counter ion in the mobile phase to improve the peak shape. The chromatography was shown in Fig. 2. The standard curve method was employed for quantification. The standard curve was $\mathrm{y}=101212 \mathrm{x}-1277.1$ in the range of 0.1 to $4 \mathrm{mg} / \mathrm{L}$ with $\mathrm{R}^{2}=0.9999$. The recovery of cyromazine in different sample matrixes was in the range of 80 to $87 \%$, while $0.2 \mathrm{mg} / \mathrm{kg}$ spiked in the cucumber and soil. The sample pretreatment was optimized as following.

Optimization of the sample pro-treatment procedure: The extractants were investigated for the two sample matrixes of cucumber and soil. Considering that cyromazine was a weak base $(\mathrm{pKa}=5.22)$, the pesticide should be soluble in aqueous acid solution. The extraction performance of $50 \mathrm{mM}$ hydrochloric acid, acetonitrile, acetonitrile-water 9:1 (v:v) and acetonitrile-50 $\mathrm{mM}$ ammonium acetate 9:1 (v:v) were studied. The recoveries were shown in Table-2. The recovery obtained with $50 \mathrm{mM}$ hydrochloric acid was $84.3 \%$ and the extractant of $50 \mathrm{mM}$ hydrochloric acid was selected in the soil analysis.

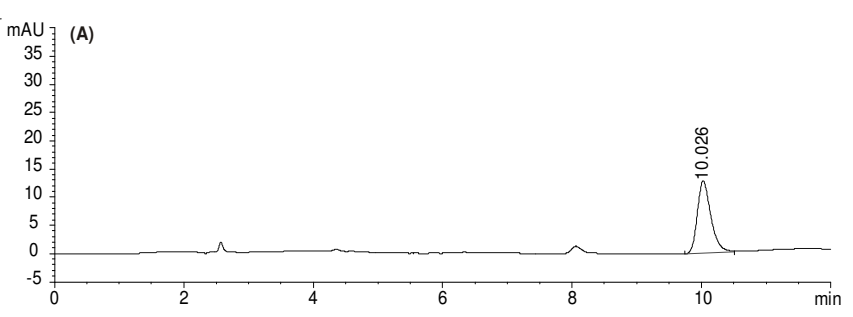



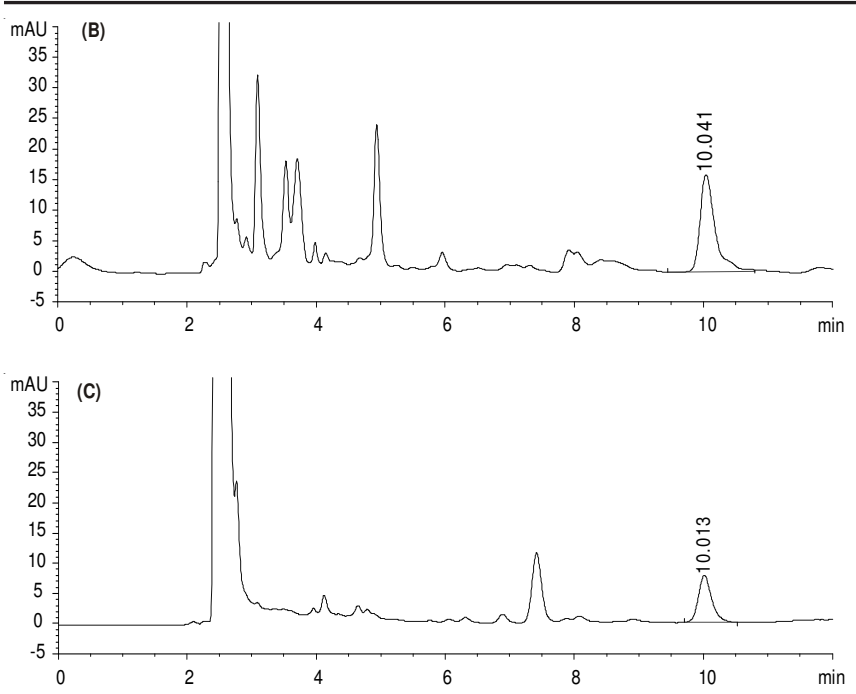

Fig. 2. Chromatographs of cyromazine $2 \mathrm{mg} / \mathrm{kg}$ stands (A); actrual detective value of cyromazine in cucumber (B); actrual detective value of cyromazine in soil (C)

\begin{tabular}{|c|c|c|c|c|c|}
\hline \multicolumn{6}{|c|}{$\begin{array}{c}\text { TABLE-2 } \\
\text { RECOVERY OF CUCUMBER EXTRACTANTS }\end{array}$} \\
\hline \multirow{2}{*}{ Extractants } & \multirow{2}{*}{ Matrix } & \multicolumn{4}{|c|}{ Recoveries (\%) } \\
\hline & & I & II & III & Average \\
\hline \multirow{2}{*}{$\begin{array}{l}50 \mathrm{mM} \text { Hydrochloric } \\
\text { acid }\end{array}$} & Cucumber $^{\mathrm{b}}$ & I & I & I & I \\
\hline & Soil & 84 & 85 & 84 & 84.3 \\
\hline \multirow{2}{*}{ Acetonitrile } & Cucumber & 64 & 60 & 59 & 61.0 \\
\hline & Soil & 78 & 80 & 84 & 80.7 \\
\hline \multirow{2}{*}{ Acetonitrile: water $=9: 1$} & Cucumber & 68 & 72 & 65 & 68.3 \\
\hline & Soil & 82 & 86 & 81 & 83.0 \\
\hline \multirow{2}{*}{$\begin{array}{l}\text { Acetonitrile: } 50 \mathrm{mM} \\
\text { ammonium acetate }=9: 1\end{array}$} & Cucumber & 80 & 78 & 82 & 80.0 \\
\hline & Soil & 84 & 83 & 83 & 83.3 \\
\hline
\end{tabular}

Since the cucumber was more complex, the sample extracted by acid solution could not be separated cyromazine from impurities; the method was not employed in cucumber analysis. The sample treated with $50 \mathrm{mM}$ hydrochloric acid could obtained the recovery of $84 \%$ which was relatively higher than those done by acetonitrile- $50 \mathrm{mM}$ ammonium acetate 9:1 (v:v) in soil. Since less organic solvent was employed in the present soil sample analysis, $50 \mathrm{mM}$ hydrochloric acid was used as extractants in the soil sample analysis.

The recoveries in cucumber were distinguished from one to each other. Ammonium acetate in the extractant improved the recovery for it's interaction with the polar cyromazine molecular. The recoveries were from 80.7 to $87.9 \%$. The newly detection data were obtained as shown in Table-2, which provided more real and more accurate data to describe the recovery of this method. The extractant of acetonitrile- $50 \mathrm{mM}$ ammonium acetate 9:1 (v: v) was employed in the cucumber sample anaysis.

Cleaning up: $\mathrm{C}_{18}$, Florisil and silica gel cartridges were compared for cleaning-up. It was found that $\mathrm{C}_{18}$ and Florisil could not separate cyromazine form the impurities successfully (figures not given). Silica gel cartridges might do the work well. The eluation was carried with mixed solvent of methanol and dichloromethane. It was proved that the eluting performance increased with increasing methanol proportion. The target would not be eluted until $25 \%$ methanol was used. Fig. 3 described the trend of recovery curves along with methanol proportion. When methanol-dichloromethane $>1: 3(\mathrm{v}: \mathrm{v})$, the recoveries of cyromazine were not significantly increased. In the sample analysis, 3:1 (v:v) methanol-dichloromethane was employed as eluting solvent.

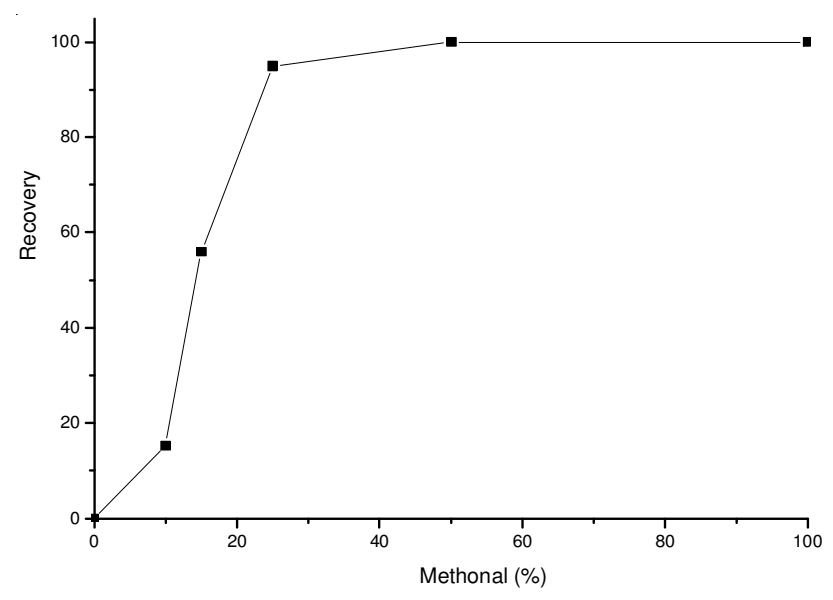

Fig. 3. Optimization of eluting proportion

Degradation of cyromazine: To investigate the degradation characters of the pesticide, the degradation properties of cyromazine in the cucumber and soil of three locations were investigated. With time increasing, the decrease in concentration was observed. The degradation curves were fitted with first order dynamics and the results shown in Fig. 4. The degradation in cucumber was relatively faster than that in soil considering the photo-degradation and grown dilution effect. For example, the half-life in cucumber was $7.3 \mathrm{~d}$ in cucumber, while it was 15.2 in soil in Beijing samples.

In cucumbers, the degradation in Hainan is the fastest in cucumber considering highest temperature and sun-light and the half-lives was in $7.3 \mathrm{~d}$ in Beijing, $6.3 \mathrm{~d}$ in Anhui and 5.2 in

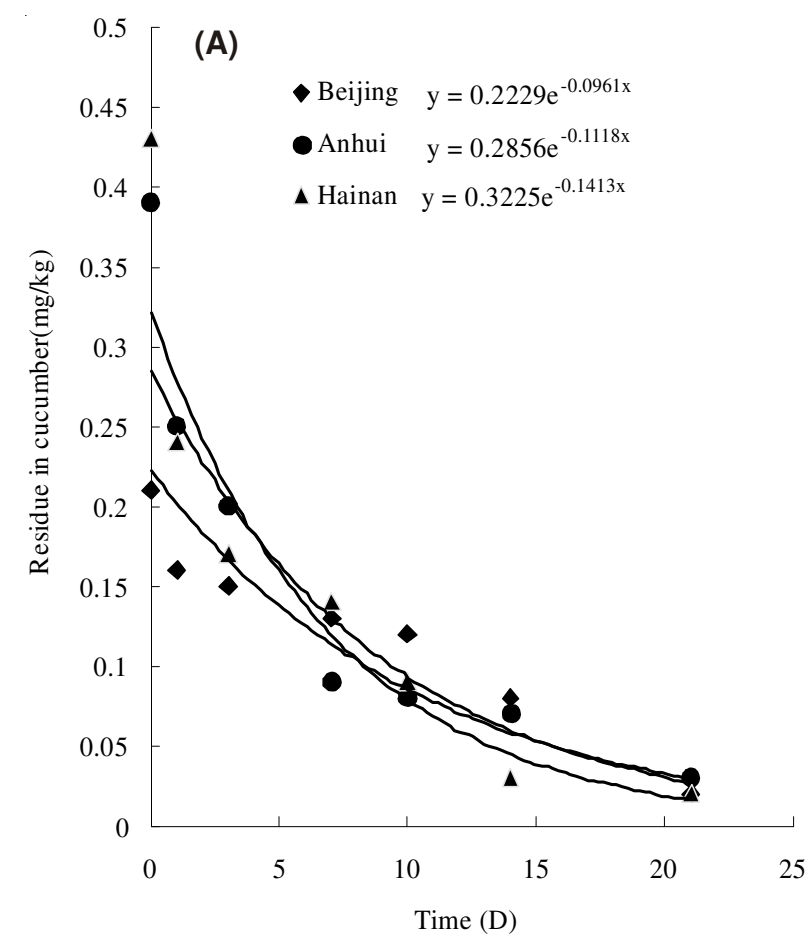




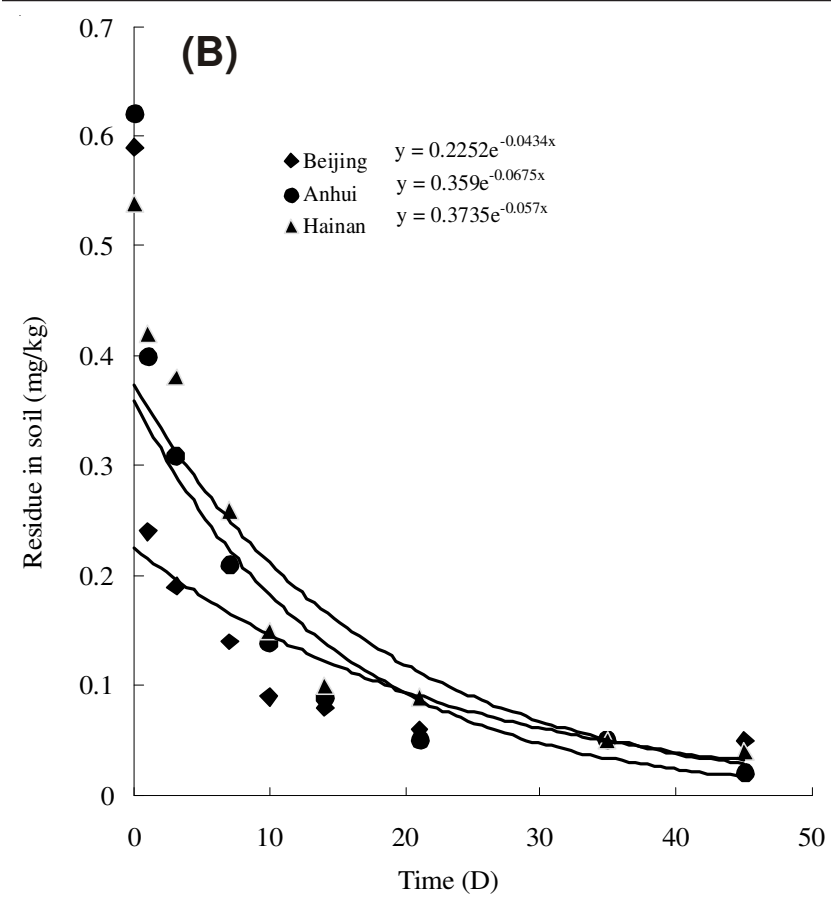

Fig. 4. Degradation curves of cyromzine in cucumber (A) and in soil (B) in Beijing, Anhui, Hainan

Hainan in cucumbers. In soil, the degradation in Beijing samples was relatively slower than that in other place for the soil leaching by rainfall and relatively lower soil microorganisms activity in Beijing considering lower temperature and rainfall and the half-life was $15.3 \mathrm{~d}$ in Beijing, 9.2 in Anhui and $10.1 \mathrm{~d}$ in Hainan in soil.

Ultimate in cucumber and soil: The ultimate levels in cucumber and soil were tested under the sparing dosages of $225 \mathrm{~g}($ a.i. $) /$ ha (the recommended dosage) and $337.5 \mathrm{~g}($ a.i. $) / \mathrm{ha}$ ( 1.5 folds to recommended dosage) for two and three times respectively. According to the definition, the pro-harvestinterval would be defined as the time scare after the residue decreased below the level of the recommended maximum residual limit (MRL, $0.2 \mathrm{mg} / \mathrm{kg}$ in China). As shown in Fig. 5, the residue level was associated with the factors of the application dosage and repeated usage. The higher residue level was often observed when higher dosage or more times usages. The residue level of cyromazine was below maximum residual limit of $0.2 \mathrm{mg} / \mathrm{kg}$ after 2 days under most conditions and until 3 days, the entire residue was below $0.2 \mathrm{mg} / \mathrm{kg}$. Same as in the degradation investigation, the pesticide decreased faster in Hainan than in Beijing and Anhui.

The final residue level in soil was investigated as well. The soil was sampled around the cucumber. The residue in Beijing was in the range of $0.05 \mathrm{mg} / \mathrm{kg}-0.09 \mathrm{mg} / \mathrm{kg}$ after 3 days and $0.07 \mathrm{mg} / \mathrm{kg}-0.11 \mathrm{mg} / \mathrm{kg}$ in Anhui and $0.05 \mathrm{mg} / \mathrm{kg}$ $0.10 \mathrm{mg} / \mathrm{kg}$ in Hainan. The pesticide could be detected after 7 days although the concentration was in the range of 0.03 to $0.06 \mathrm{mg} / \mathrm{kg}$. It was indicated that the repeated usage of the pesticide could not only induced residue increase in the cucumber, the increase in the burden of cultured soil as well.

\section{Conclusion}

In the present work, the analysis method of HPLC for cyromazine in cucumber and soil was developed. The newly
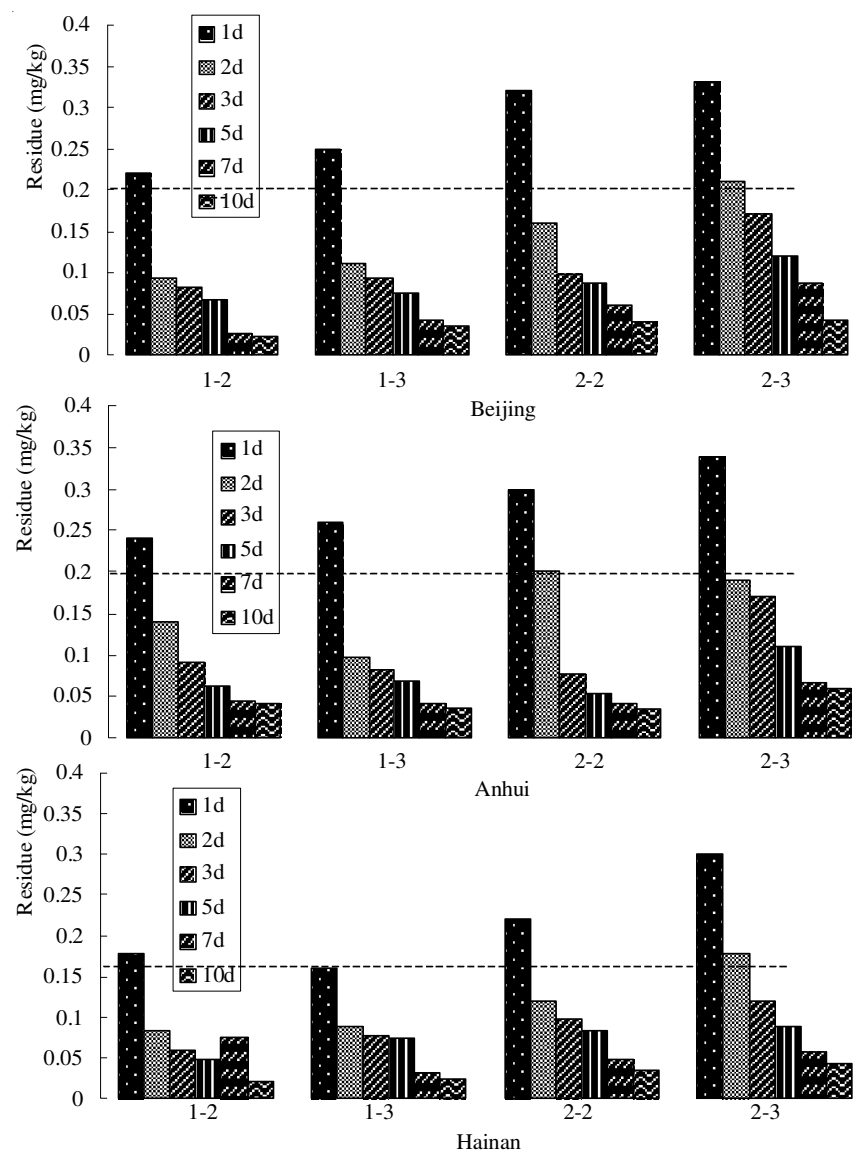

Fig. 5. Ultimate in cucumber in Beijing, Anhui and Hainan

extraction method for cyromazine was developed as well based on the aqueous extractant which reduced the organic solvent usage in the pesticide analysis. The method established in this paper provides a tool to monitor cyromazine residues in cucumber and soil and provide the information to the farmer to properly spray cyromazine into cucumbers.

The degradation of the pesticides was investigated The declining kinetics of cyromazine was in accord with one order reaction kinetics equation and the average half-life of cyromazine in cucumber was 5.2-7.3 days and in soil was of 10.1-15.3 days. The pro-harvest-interval was 3 days based on the experiments in the three locations considering maximum residual limit of $0.2 \mathrm{mg} / \mathrm{kg}$.

\section{ACKNOWLEDGEMENTS}

This work has been funded by the Innovative Program of the Chinese Academy of Sciences (KZCX2-YW-JS403).

\section{REFERENCES}

1. R.A. Yokley, L.C. Mayer, M.E. Rezaaiyan and M.W. Manuli, J. Agric. Food Chem., 48, 3352 (2000).

2. A.M. Cook and R.S. Hutter, J. Agric. Food Chem., 29, 1135 (1981).

3. J.P. Toth and P.C. Bardalaye, J. Chromatogr. A, 408, 335 (1987).

4. J.V. Sancho, M. Ibanez, S. Grimalt and F. Hernandez, Anal. Chim. Acta, 530, 237 (2005).

5. S.S. Chou, D.F. Hwang and H.F. Lee, J. Food Drug Anal., 11, 290 (2003).

6. R. Wang, T.Z. Liu and W.R. Liu, Acta Agric Zhejiangensis, 17, 376 (2005).

7. H. Sun, L. Wang, N. Liu, F. Qiao and S. Liang, Chromatographia, 70, 1685 (2009). 